\title{
Promising Initial Results of CAR T-Cell Therapy in Refractory Large B-Cell Lymphoma
}

\author{
Luis Mendoza*
}

*IQVIA Senior Medical Director, Medical Strategy \& Science, Oncology-Hematology Therapeutic Science \& Strategy Unit, Czech Republic

Received: 18 December, 2017; Accepted: 27 December, 2017; Published: 29 December2017

*Corresponding author: Luis Mendoza, IQVIA, Senior Medical Director, Medical Strategy \& Science, Oncology- Hematology Therapeutic Science \& Strategy Unit, Czech Republic; Tel: +420 778700 845: E-mail: luis.mendoza@iqvia.com

\section{Editorial}

Diffuse large B-cell lymphoma (DBLC) is the most common form of non-Hodgkin lymphomas. Patients with DBLC who have a relapse with chemotherapy-sensitive disease may be treated with high-dose chemotherapy followed by autologous stem-cell transplantation. However, the prognosis of patients whose diseases chemotherapy resistant, refractor to primary or salvage chemo-immunotherapy, or who have had a relapse after transplantation, is extremely poor. In October 2017, the U.S. Food and Drug Administration (FDA) approved the newest type of immunotherapy called axicabtageneciloleucel, Yescarta ${ }^{\mathrm{TM}}$ (Gilead Sciences)to treat adult patients with certain types of large B-cell lymphoma (non-chemotherapy refractory) who have relapsed after at least two other kinds of treatment. Yescarta ${ }^{\mathrm{TM}}$ is an autologous anti-CD19 chimeric antigen receptor (CAR) T-cell therapy.

In a phase 1 multicentre study (ZUMA-1) (1) involving seven patients, the results have shown that Yescarta ${ }^{\mathrm{TM}}$ is active and safe in the treatment of refractory large B-cell lymphoma.

In a new multicentre phase 2 trial, Sattva S Neelapu et al. (2) enrolled 111 patients with histologically confirmed refractory large B-cell lymphoma, including diffuse large B-cell lymphoma and primary mediastinal B-cell lymphoma, who received at least one previous line of treatment. Between November, 2015, and September, 2016, the enrolled patients received conditioning treatment (low-dose cyclophosphamide, $500 \mathrm{mg} / \mathrm{m} 2$ per day, and fludarabine, $30 \mathrm{mg} / \mathrm{m} 2$ per day) on days 5 , 4, and 3 before administration of autologous CAR T cells expressing anti-CD19 at a dose of $2 \times 10^{*} 6$ cells per kg of bodyweight. The primary endpoint was the proportion of patients with an objective response.

At the data cut-off (27 January 2017) for the primary analysis, the median follow-up was $8 \bullet 7$ months. Eighty-three (82\%; 95\% CI 73-89) of 101 patients included in the intention-to-treat analyses had an objective response, with 55 (54\%) patients achieving a complete response and 28 (28\%) partial responses. An updated analysis at a median follow-up of $15 \bullet 4$ months (cut-off date August 11, 2017) including 108 evaluable patients showed a median progression-free survival of $5 \bullet 8$ months $(95 \%$ CI $3 \bullet 3-$ not reached). Median overall survival was not reached (12•0-not reached). The most common adverse events during the treatment were pyrexia in $86(85 \%)$ of 101 patients, neutropenia in 85 $(84 \%)$ patients, and anaemia in $67(66 \%)$ patients. Four patients died during the treatment, two due to progressive disease and two from adverse events. The median overall survival had not been reached, with an overall survival rate at 18 months of $52 \%$. Ongoing durable remissions were observed in patients at 24 months. These results, combined with the observation of ongoing long-term remissions beyond four years in the previous study (3), suggest that Yescarta ${ }^{\mathrm{TM}}$ provides substantial clinical benefit for patients with refractory disease.

Looking for better efficacy results, a combination trial of Yescarta $^{\mathrm{TM}}$ with anti-PD-L1 antibody, atezolizumab (Genentech/ Roche), is ongoing. The initial results presented at the ASH (American Society of Hematology) meeting of this year (3), reporting PD-L1 blockade with atezolizumab following Yescarta ${ }^{\text {TM }}$ infusion, appeared to have a manageable safety profile. A prospective randomised trial will be initiated next year to directly compare the efficacy of Yescarta ${ }^{\mathrm{TM}}$ plus autologous stem cell transplantation in patients with large B-cell lymphoma experiencing a first relapse.

\section{References}

1. Locke FL, Neelapu SS, Bartlett NL, et al. Phase 1 results of ZUMA-1: a multicenter study of KTE-C19 anti-CD19 CAR T cell therapy in refractory aggressive lymphoma. MolTher 2017;25:285-295

2. Sattva S. Neelapu, M.D., Frederick L. Locke, M.D.et al. AxicabtageneCiloleucel CAR T-Cell Therapy in Refractory Large B-Cell Lymphoma. N Engl J Med 2017 Dec 10. doi: 10.1056/NEJMoa1707447

3. Kochenderfer JN, Somerville RPT, Lu T, Yang JC, Sherry RM, Feldman $\mathrm{SA}$, et al. Long-duration complete remissions of diffuse large B cell lymphoma after anti-CD19 chimeric antigen receptor T cell therapy. MolTher. 2017;25(10):2245-2253. Doi: 10.1016/j.ymthe.2017.07.004

4. Phase 1 Results from ZUMA-6: AxicabtageneCiloleucel (axi-cel; KTE-C19) in Combination with Atezolizumab for the Treatment of Patients with Refractory Diffuse Large B Cell Lymphoma (DLBCL). ASH 2017; Abstract 2826

Citation: Luis M (2017) Promising Initial Results of CAR T-Cell Therapy in Refractory Large B-Cell Lymphoma. Int J Hematol Blo Dis 2(3). 1-2. 